\title{
1 Optimal strategies for monitoring irrigation water quality
}

2 Nathan Lothrop ${ }^{1}$, Kelly R. Bright ${ }^{2}$, Jonathan Sexton ${ }^{1}$, Jennifer Pearce-

$3 \quad$ Walker $^{1}$, Kelly A. Reynolds ${ }^{1}$, Marc P. Verhougstraete ${ }^{1^{\star}}$

4

$5 \quad{ }^{1}$ Mel and Enid Zuckerman College of Public Health, The University of Arizona

$6 \quad{ }^{2}$ Department of Soil, Water \& Environmental Science, College of Agriculture and Life Sciences,

$7 \quad$ The University of Arizona

8

9

10

11

12

13

14

15 *Corresponding Author:

16 Marc Verhougstraete

171295 N. Martin Ave.

18 Tucson, AZ 85724

$19 \quad$ (520) 621-0254

20 mverhougstraete@email.arizona.edu

21 


\section{ABSTRACT}

23 The quality of irrigation water drawn from surface water sources varies greatly. This is

24 particularly true for waters that are subject to intermittent contamination events such as runoff

25 from rainfall or direct entry of livestock upstream of use. Such pollution in irrigation systems

26 increases the risk of food crop contamination and require adoption of best monitoring practices.

27 Therefore, this study aimed to define optimal strategies for monitoring irrigation water quality.

28 Following the analysis of 1,357 irrigation water samples for Escherichia coli, total coliforms, and

29 physical and chemical parameters, the following key irrigation water collection approaches are

30 suggested: 1) explore up to 950 m upstream to ensure no major contamination or outfalls exists;

31 2) collect samples before $12: 00$ PM local time; 3 ) collect samples at the surface of the water at

32 any point across the canal where safe access is available; and 4) composite five samples and

33 perform a single E. coli assay. These recommendations comprehensively consider the results as

34 well as sampling costs, personnel effort, and current scientific knowledge of water quality

35 characterization. These strategies will help to better characterize risks from microbial pathogen contamination in irrigation waters in the Southwest United States and aid in risk reduction

37 practices for agricultural water use in regions with similar water quality, climate, and canal 38 construction.

\section{HIGHLIGHTS}

- Microbial testing practices must be based on irrigation water-specific research.

- Assaying sample composites is the most cost-effective best representation of microbial content.

- Contamination events have $2-\log _{10}$ reductions $950 \mathrm{~m}$ downstream.

- Microbial concentrations are highest before noon.

- Microbial concentrations are homogenous throughout the canal water column. 
48 KEYWORDS: food crop safety; Escherichia coli; irrigation water quality; agriculture; water 49 management; monitoring guidelines

50 


\subsection{INTRODUCTION}

Historically, water quality guidelines have focused on drinking, waste, and recreational sectors, excluding waters used throughout the production of food crops. The recently developed "Standards for Growing, Harvesting, Packing, and Holding Produce for Human Consumption" establish safety guidelines for the US agriculture industry (Food and Drug Administration, 2015). Although these guidelines are scientifically based, they fail to grasp the complexity of irrigation systems and offer few suggestions for the appropriate monitoring of irrigation water safety. The US Food and Drug Administration (FDA) Food Safety Modernization Act (FSMA) includes microbiological rules for irrigation water that are based on epidemiological studies undertaken at ocean and freshwater beaches. Little evidence exists that relates FSMA to the associated risks for fresh produce and irrigation waters. FSMA guidelines require untreated surface water used for irrigation be tested for Escherichia coli (E. coli) 20 times over 2-4 years and then $<5$ times annually. In water used for any purpose besides the growing of sprouts, hand washing, or direct application to food surfaces, E. coli concentrations cannot exceed 126 colony forming units (CFU)/100 ml, using a geometric mean of at least five samples taken over multiple days (e.g., a monthly geometric mean) or $410 \mathrm{CFU} / 100 \mathrm{ml}$ in a single sample (i.e., a statistical threshold value [STV]). If the E. coli concentration exceeds this STV, the water can still be used to irrigate food crops if an appropriate time prior to harvest is allowed, assuming a $0.5-\log _{10}$ die-off of $E$. coli per day. For water used in sprout irrigation, applied directly to food surfaces, or used for hand washing, E. coli regulations are as stringent as for drinking water (i.e., $0 \mathrm{CFU} / 100 \mathrm{ml}$ ). If $E$. coli concentrations exceed any of these thresholds, the water cannot be used for irrigation (Food and Drug Administration, 2015). These rules aimed at food safety fail to take under consideration the rapid spatial and temporal changes of microbial concentrations in water.

Water research undertaken in rivers, lakes, oceans, reservoirs, and irrigation canals has routinely demonstrated significant changes in microbe concentrations on short spatial and 
77

temporal scales (Boehm, 2007; Haack et al., 2004; Juahir et al., 2011; Song et al., 2012; Verhougstraete and Rose, 2014; Won et al., 2013). For instance, one study determined that Enterococcus concentrations at California beaches typically varied by $60 \%$ over 10 minutes, but could vary by as much as $700 \%$ (Boehm, 2007). Similarly, the FDA guidelines fail to consider the spatial variations of microbial water quality, potentially leaving the food product vulnerable to contamination.

Bacterial concentrations undergo rapid change along stream length, throughout the vertical water column (Agogué et al., 2011; Karl, 1978; Krempin and Sullivan, 1981; Llirós et al., 2010), and across stream width (Byappanahalli et al., 2003; Jones et al., 1995; Whitman et al., 2006). Thus, a single sample may not provide an adequate representation of the true microbial water quality in an irrigation water canal. Water quality scientists have also noted the implications of a single sample versus multiple samples for management actions (e.g., opening or closing of a beach) (Bertke, 2007; Reicherts and Emerson, 2010). Kinzelman et al. (2006) determined that compositing multiple lake water samples and assaying with a single test was not statistically different $(P>0.02)$ than analyzing multiple individual samples and reporting an average; both approaches called for similar management actions. The benefits of compositing samples include the ability to collect multiple samples from various locations (more representative of water quality) and reduced costs (by performing a single test), while still providing at least the same level of protection as collecting single or multiple samples. Considering previous research in non-irrigation systems, it is inadequate to base the safety of an entire irrigation canal on the results of a single sample.

In addition to the numerous surface water studies previously mentioned, irrigation waters have been examined for microbial contamination. Fecal indicator bacteria (e.g. total coliforms, E. coli, enterococci), Salmonella spp., Staphylococcus aureus, Microsporidia, Giardia, 
and Cryptosporidium, Noroviruses, Campylobacter spp., and Clostridium perfringens have been measured in irrigation waters throughout the world (Gerba and Choi, 2006; ljabadeniyi et al., 2011; Kayed, 2017; Thurston-Enriquez et al., 2002). One study found irrigation water is a major risk factor for bacterial contamination of fresh lettuce due to the detection of $E$. coli and Campylobacter. spp. (Holvoet et al., 2014). Irrigation water and food safety concerns are further highlighted by a study that demonstrated hepatitis A virus and Salmonella present in water used to irrigate iceberg lettuce was associated with exceedances of the U.S. Environmental Protection Agency's acceptable annual risk level of 1:10,000 (Stine et al., 2005). Produce commonly grown using irrigation water includes corn, orchard crops, and vegetables, all of which have to potential to be consumed raw and further increasing the potential for infection from contaminated irrigation water (“USDA Economic Research Service," 2017). Together, these studies represent the diversity of microbial water quality and the importance of understanding irrigation water quality to protect fresh produce.

To help ensure adequate water safety and reduce the risks for agricultural water, microbial testing practices must be based on irrigation water-specific research, not adapted from drinking and recreational water studies. This is critically important given that during the winter months, more than $90 \%$ of all leafy greens consumed in the US are grown in the Southwest region of Yuma, AZ (http://bit.ly/2jhuwb1, accessed on 8 February 2017). In addition, Southern California produces $15 \%$ of the lettuce and leafy greens consumed by the US overall (http://bit.ly/2k4ceHK, accessed on 8 February 2017). Due to the importance of this region for fresh produce production and the current knowledge gaps in irrigation water quality science, this study aimed to better understand the spatial and temporal variations of microbial concentrations in irrigation canals, to produce a comprehensive monitoring plan, and to reduce pathogen exposure risks at the point of irrigation water application to food crops. To this end, there were four study objectives: 1) determine the most effective time of day for irrigation water 
monitoring; 2) define canal cross-sectional sampling locations; 3) delineate the transport of microorganisms in irrigation canals; and 4) determine the suitability of collecting single, multiple, or composite irrigation water samples for analysis.

\subsection{MATERIALS AND METHODS}

\subsubsection{Site location}

Sampling sites were selected following discussions with scientists from the University of Arizona and local agricultural extension centers. Samples were collected from a total of 93 unique sites among Yuma and Maricopa Counties, AZ and Imperial County, CA in the southwestern US. Sampling sites included a mixture of main, lateral, and sub-lateral canals and both cement-lined and unlined canals with varying flow dynamics. In addition, some locations were located in urban and others in rural areas.

\subsubsection{Field Analysis and Sample collection}

For all samples, the water temperature, air temperature, conductivity, total dissolved solids, $\mathrm{pH}$, and relative humidity were measured in the field using the Multiparameter PCS Testr 35 (Oakton Instruments, Vernon Hill, IL) and the Fisherbrand Traceable Memory Hygrometer/Thermometer (Thermo Fisher Scientific, Waltham, MA). Samples were placed on ice in a cooler and transported to the laboratory for microbial processing and additional analyses (e.g., turbidity). Continuously recorded environmental variable data (wind speed and direction, barometric pressure, and antecedent precipitation) from National Weather Service stations were retrieved from the University of Utah's MesoWest interface (MesoWest, http://mesowest.utah.edu/, accessed on 10 December 2015).

To account for seasonal variations in microbial concentrations, weather variability, crop production, and water use practices, grab samples were collected between December 2014 and 
November 2015 using sterile 1L wide-mouth HDPE bottles (Nalgene Co., Rochester, NY). The depth below surface, the distance from the bank, the time of day, and collection location were study objective-dependent as detailed below.

To determine the most suitable time of day for irrigation water sampling, grab samples were collected $0.15 \mathrm{~m}$ below the water surface near the canal bank at the same site four times per day (i.e., before 09:00, 09:00-12:00, 12:00-13:00, and after 13:00). To define appropriate collection points in a canal cross-section, grab samples were collected vertically through the canal water column (at the water surface and $0.61 \mathrm{~m}$ and $1.22 \mathrm{~m}$ below the surface) and horizontally across canal transects (at both banks and $1 / 4$ of the distance of the canal width from each bank). A schematic of this sampling approach is presented in Figure 1. To determine the best collection, processing, and results representation approach, three sampling approaches were investigated: approach A included collecting a single sample from a single collection point at $0.33 \mathrm{~m}$ from the canal bank and $0.15 \mathrm{~m}$ below the water surface; approach $\mathrm{B}$ involved collecting five samples from the same canal stretch $(0.15 \mathrm{~m}$ below the water surface and $0.33 \mathrm{~m}$ from the canal bank, $2 \mathrm{~m}$ apart), assaying each sample individually, and calculating a geometric mean of the five samples; and approach C involved collecting five samples from the same canal stretch ( $0.15 \mathrm{~m}$ below the water surface and $0.33 \mathrm{~m}$ from the canal bank, $2 \mathrm{~m}$ apart), adding equal 20-ml volumes of well-mixed aliquots from each discrete sample to a sterile bottle to form a composite sample, then assaying in an identical manner to a single sample $(100 \mathrm{ml}$ total) and reporting the results as a single value. Diagrams of these sampling collection approaches are shown in Figure 2.

To better understand the transport of microorganisms in irrigation systems, total coliforms and E. coli were measured following the same plug of canal water as it traveled downstream in three different canals using a flow tracking bottle. Grab samples of this same plug of water were 
181

182 183 184 185 186 187 188 189 190 191 192 193 194 195 196 197 198 199 200 201 202 203 204 testing.

collected using sterile 1 L HDPE wide-mouth bottles downstream at distances of $0 \mathrm{~m}, 322 \mathrm{~m}$, $644 \mathrm{~m}, 966 \mathrm{~m}, 1288 \mathrm{~m}, 1609 \mathrm{~m}, 1931 \mathrm{~m}$, and $2253 \mathrm{~m}$ from the designated starting point. The bacterial transport experiments were performed five times per canal.

Additionally, coliphage MS2 (ATCC 15597-B1; American Type Culture Collection, Manassas, VA) was used to seed the same three canals (one experiment per canal) to serve as a microbial tracer organism. This non-pathogenic virus has been used as a surrogate for many pathogens in various environments (Reynolds et al., 2015; Sinclair et al., 2009; Valdez et al., 2015). A 200$\mathrm{ml}$ volume of MS2 coliphage at a concentration of approximately $1 \times 10^{12}$ plaque forming units (PFU) was mixed with $20 \mathrm{~L}$ of canal water. This mixture was dispersed across the width of the canal and the plug of water containing the MS2 was followed downstream using a flow tracking device. Grab samples of this same plug of water were collected as before at distances of $0 \mathrm{~m}$, 322 m, 644 m, 966 m, 1288 m, 1609 m, 1931 m, and 2253 m from the seeding point, in addition to $81 \mathrm{~m}, 161 \mathrm{~m}$, and $241 \mathrm{~m}$ to limit the potential for non-detection in measurements taken further from the seeding point. The bacterial and viral tracer samples were placed on ice in a cooler and transported to the laboratory for processing and assay.

\subsubsection{Laboratory Analyses}

E. coli and total coliforms were enumerated in all water samples using the Colilert Quanti-Tray ${ }^{\circledR}$ (IDEXX Laboratories, Westbrook, ME) most probable number (MPN) method following the manufacturer's instructions. Following incubation at $37^{\circ} \mathrm{C}$ for $24 \pm 2$ hours, yellow wells were recorded as positive for total coliforms and wells fluorescing "blue" under ultraviolet (UV) light were recorded as positive for E. coli. Positive and negative controls were used in coliform 
Coliphage samples were serially diluted with sterile phosphate-buffered saline (PBS; pH 7.4;

207 Sigma-Aldrich, St. Louis, MO) to create $10,1,10^{-1}, 10^{-2}, 10^{-3}$, and $10^{-4} \mathrm{ml}$ duplicate subsamples.

208 Double agar layers of tryptic soy agar (Difco, Sparks, MD) were utilized to detect MS2 coliphage 209 on its specific host bacterium (E. coli ATCC 15597) following the double agar overlay method 210 (Adams, 1959; Abbaszadegan et al. 1997). Clearings in the host lawn were counted and 211 reported as PFU/100 ml. Sterile reagent water was used as a negative control for verification of 212 the method integrity. MS2 coliphage background measurements were taken before seeding in 213 the canal.

\subsubsection{Statistical Analyses}

216 All bacterial data were log transformed prior to performing statistical analyses to minimize 217 skewness and to ensure a normal distribution. Pearson Correlation analysis was used to identify 218 relationships between microbial concentrations and independent variables (e.g., physical, 219 chemical, weather, canal discharge rates). A significance level cutoff of $\alpha=0.05$ was used for all 220 correlative statistical tests. Stata Statistical Software (StataCorp, College Station, TX) was used 221 for traditional statistical analyses, including Two-tailed t-tests, Kruskal-Wallis tests, Wilcoxon 222 signed-rank tests, and Spearman's rank correlation tests.

\subsection{RESULTS AND DISCUSSION}

225 A total of 1,328 samples were collected from 84 unique sites and were measured for E. coli, 226 total coliforms, $\mathrm{pH}$, conductivity, turbidity, total dissolved solids (TDS), air temperature, water 227 temperature, and relative humidity. Summary results for these water quality measurements by 228 region are provided in Table 1 . Across all 1,328 sites, statistically significant correlations were 229 identified between $E$. coli and air temperature $(r=0.13, P=0.0003)$, water temperature $(r=$ $2300.26, P<0.0001)$, relative humidity $(r=-0.23, P<0.0001), \mathrm{pH}(r=0.15, P<0.0001)$, 
231

232

233

234

conductivity $(r=-0.20, P<0.0001)$, turbidity $(r=-0.29, P<0.0001)$, and TDS $(r=-0.20, P<$ 0.0001). From an additional 9 unique sites, 29 samples were measured for coliphage.

The first objective of this study was to determine the appropriate time of day for irrigation water monitoring. Samples $(n=802)$ were collected at the same location on the same day at four different time points: before 09:00 $(n=185)$, between 09:00-12:00 $(n=222)$, between 12:0013:00 $(n=173)$, and after 13:00 $(n=222)$. Overall, E. coli ranged from $0.5 \mathrm{MPN} / 100 \mathrm{ml}$ to $>2419.6 \mathrm{MPN} / 100 \mathrm{ml}$ [geometric mean $(\mathrm{GM})=20.2 \mathrm{MPN} / 100 \mathrm{ml}$ ] and total coliforms ranged from 77.1 MPN/100 ml to >2419.6 MPN/100 ml (GM = $821 \mathrm{MPN} / 100 \mathrm{ml})$. Results for $E$. coli and total coliforms in samples collected by time of day are shown in Table 2 . While there were statistically significant differences between samples collected in the morning versus the afternoon, the most statistically significant difference between the samples collected for $E$. coli (Two-tailed t-test, $P<0.0001$ ) was between those collected from 07:00-12:00 versus 12:0016:00, with higher $E$. coli concentrations detected in the morning (GM $=24.8 \pm 164 \mathrm{MPN} / 100$ $\mathrm{ml}$ ) compared to the afternoon $(\mathrm{GM}=15.4 \pm 117 \mathrm{MPN} / 100 \mathrm{ml})$. No such relationship was found with total coliforms.

Morning is thus the most conservative time to sample which supports previous studies (Lubo Liu et al., 2006; Whitman et al., 2004). In addition, the microbial water quality in the Southwest likely benefits from the high solar radiation levels previously shown to reduce bacterial concentrations. The Southwest has the highest solar radiation levels in the US (National Renewable Energy Laboratory, 2009). Therefore, the bacterial numbers would be expected to be reduced during the daytime hours with increasing exposure to the sun.

The second study objective was to determine the appropriate sample collection point within the cross-section of canals based on multiple spatial samples (Figure 1). E. coli measurements 
were grouped in all combinations of depth and distance to the bank and the means were compared. Overall, E. coli ranged from $<1.0$ to 1,550 MPN/100 ml (GM = 8.4 MPN/100 ml). E. coli in the top, middle, and bottom horizontal transects ranged from $<1.0$ to $792 \mathrm{MPN} / 100 \mathrm{ml}$ $(\mathrm{GM}=8.32 \mathrm{MPN} / 100 \mathrm{ml}),<1.0$ to $1,300 \mathrm{MPN} / 100 \mathrm{ml}(\mathrm{GM}=8.9 \mathrm{MPN} / 100 \mathrm{ml})$, and $<1.0$ to 1,550 MPN/100 ml (GM = 7.97 MPN/100 ml), respectively. E. coli ranged from $<1.0$ to 1,410 MPN/100 $\mathrm{ml}(\mathrm{GM}=8.33 \mathrm{MPN} / 100 \mathrm{ml})$ near the canal banks and from $<1.0$ to $1,550 \mathrm{MPN} / 100$ $\mathrm{ml}(\mathrm{GM}=8.45 \mathrm{MPN} / 100 \mathrm{ml})$ in the center of the canals. There were no statistically significant differences between depth groups (Kruskal-Wallis test, $P=0.76$ ), transect vs. bank groups (Wilcoxon rank-sum test, $P=0.73$ ), any depth by transect group (Wilcoxon rank-sum tests, $P>$ 0.45), or any transect by depth group (Wilcoxon rank-sum tests, $P>0.70$ ). Results for $E$. coli measurements at cross section points are provided in Table 3.

Results from this objective demonstrate homogenous microbial concentrations throughout the canals. No previous studies were identified that measured bacterial concentrations in irrigation canal transects. However, previous research conducted in non-irrigation water matrices demonstrated point source pollution and sediment resuspension produced rapid microbial concentration fluxes within the water column which return to a homogenous state over space and time (McDaniel et al., 2013; Pandey and Soupir, 2014; Pandey et al., 2016; Rehmann and Soupir, 2009). In the current study, the homogeneity of E. coli concentrations likely indicates minimal direct fecal contamination, sediment presence, or sediment resuspension in the studied canals. Confirming this will require additional research. Based on these results, we suggest irrigation monitoring samples be collected wherever safe access is achievable.

The third study objective was to address the transport of microorganisms in irrigation canals.

The initial approach involved enumerating $E$. coli and total coliforms from grab samples collected in three different irrigation canals a total of five times each. However, samples $(n=40$ 
per canal) taken from a plug of water and analyzed for E. coli and total coliforms did not produce a clear pattern of transport properties in these three canals (Table 4). To enhance this objective, additional samples $(n=29)$ were analyzed as part of a MS2 virus tracer seeding experiment using three canals (Table 5). MS2 coliphage concentrations ranged from $<0.1$ to 182,000 PFU/100 ml with an overall geometric mean of 608 PFU/100 ml.

The MS2 coliphage tracer highlights the amount of mixing and dilution that occurs in canals over long stretches. While these can vary greatly from canal to canal, there is a statistically significant negative relationship between distance from the seed point and coliphage concentration

292 (Spearman's rank correlation, rho $=-0.91, P<0.0001$ ). MS2 concentrations dropped gradually with increasing distance from the canal seeding point, as shown in Table 5. A $1-\log _{10}$ reduction in the viral tracer concentration was observed roughly $161 \mathrm{~m}$ downstream of the seeding point and a $2-\log _{10}$ reduction was observed by $966 \mathrm{~m}$ downstream. Differences in dilution effectiveness may be attributable to canal characteristics such as discharge velocity or lining type, or to

297 atmospheric factors including wind speed or precipitation. Meanwhile, E. coli and total coliform concentrations showed no discernable pattern with increasing distance from the first measurement point (Table 4). Additional testing is needed to better understand the factors that promote dilution and mixing of a microbial contamination event in irrigation canals.

301

The fourth study objective was to determine if the best approach was to collect and report a single sample or to collect five separate samples and assay them individually (reporting a geometric mean) or as a composite (Figure 2). The results from a composite of five samples was 305 found to be significantly different from both a single sample $(P=0.036)$ and also from the 306 geometric mean of the five samples tested individually $(P=0.005)$ (Wilcoxon signed-rank test). 307 Monitoring approaches that collect a single water sample will typically fail to meet a very broad 308 coefficient of variation; however, collecting and processing multiple samples to provide 
adequate representation of water quality may be cost prohibitive. A composite sample is a costeffective alternative to testing a single or multiple samples individually. In the current study, a composite sample was the most representative sampling option of the water quality within a

312 canal, in that it provides more information than a single sample while minimizing the effects of 313 outlying data (high or low bacterial numbers that can lead to a misrepresentation of the water 314 quality in a single sample or in multiple samples that are heavily influenced by one sample with 315 outlying numbers) (Figure 3). In addition, a composite sample requires only nominally more time 316 and money to collect and analyze than a single sample.

318 Composite sampling can significantly reduce the analytical costs by reducing the number of samples while increasing the likelihood of capturing the high variation inherent to microbe concentrations in water that would likely be missed with a single sample. Previous surface water studies have shown that composite samples provide better protection of human exposure to elevated bacteria concentrations compared to a single sample (Reicherts and Emerson, 2010;

323 Whitman and Nevers, 2004). However, even using composite samples, a sampling strategy 324 requiring five sampling events per year will not adequately protect produce safety considering 325 the high variability potential of bacteria in water (Boehm, 2007; Verhougstraete and Rose, 326 2014). In any irrigation water sampling approach, it is important that applied strategies are 327 empirically derived from local irrigation systems. Composite sampling does come at a cost and that cost has direct implications on identifying whether contamination exceeds a specific threshold. If $E$. coli concentrations exceed the FSMA 331 standards, composite sampling may dilute it with "safe" water samples, resulting in an 332 acceptable averaged result. The current project shows that water quality is homogeneous in 333 short canal stretches and therefore, elevated bacterial concentrations would be measured using 334 a single or composite sample. However, using a composite sample can help fulfill not only the 
FSMA sampling requirements but also support the overall objective of sampling: to protect food safety. Previous studies performed at recreational beaches indicate that single samples grossly over or underestimate the true E. coli concentrations in water (Whitman and Nevers, 2004). Using a more representative composite sampling strategy based on local irrigation water sampling will lead to greater monitoring effectiveness; produce more accurate risk assessments; and result in more accurate water quality management decisions (e.g. to use or not to use water 341 for irrigation).

343 Coupling the four objectives of this study, we suggest an overall sampling strategy that produces the most relevant data for determining the risks of microbial pathogen contamination of food crop waters. Through careful consideration of the entirety of our data as well as sampling costs, personnel effort, and the current state of scientific knowledge of irrigation water quality characterization, our study shows that microbial water quality is homogenous in short spatial scales (<161 m), but varies significantly both temporally (morning versus afternoon) and over long distances (> $950 \mathrm{~m}$ ). We therefore recommend that open canal irrigation water sampling in the Southwest region be undertaken while keeping the following 351 guidelines in mind:

- Explore up to 950 m upstream to ensure no major contamination or outfalls exist

- Sample before noon

357 This study was conducted in the Southwest United States and as such, the suggested monitoring

- Collect samples at any point across the canal where safe access is available

- Composite five samples and perform a single E. coli assay

359 areas that routinely experience warm air temperatures (average monthly highs of $21^{\circ} \mathrm{C}$ ) and low 
precipitation (average monthly totals of $0.97 \mathrm{~cm}$ ) during the growing season. However, the study design offers an approach for agriculture communities anywhere to better understand the spatial and temporal variations of microbial concentrations in their irrigation canals, to produce a comprehensive monitoring plan specific for their geographical region, and to reduce pathogen exposure risks at the point of irrigation water application to the regional specific food crops. One limitation of this approach is the inability to identify specific sources of microbial contamination in water using E. coli, a generic bacteria found in the feces of mammals, some birds, plants, and

367 can replicate in water outside its natural host (Mclellan et al., 2001; Whitman et al., 2005;

368 Winfield and Groisman, 2003). Additional microbial analysis, such as molecular source tracking, 369 would be required to identify specific sources of contamination. Despite this limitation, the current study suggests a comprehensive monitoring plan for irrigation water in the Southwest United States. This region plays a significant role in the supply of America's leafy green produce 372 and therefore the suggested monitoring plan will reduce pathogen exposure risks at the point of 373 irrigation water application to food crops.

\subsection{CONCLUSION}

376 The current study provides evidence-based suggestions for effective irrigation water quality 377 monitoring. These monitoring guidelines are focused on spatial and temporal monitoring 378 strategies specific to the Southwest United States and are aimed at practical applications 379 considering human health risks relative to food crop contamination via irrigation waters and 380 costs relative to sample analysis and personnel effort. More so, these suggested monitoring 381 guidelines are based on irrigation water data, not recreational water studies, as has been the 382 case in recent federal suggestions (e.g. FSMA). These suggested monitoring guidelines will 383 ultimately enhance food safety, protect human health, and reduce the potential for costly food 384 recalls stemming from produce contaminated by irrigation water. 


\section{ACKNOWLEDGEMENTS}

387 This work was funded by grants from the Center for Produce Safety (Grant \# 2015CPS05) and

388 the Arizona Department of Agriculture's Specialty Crop Block Grant Program (Grant \# SCBGP-

389 FB14-01).

390

391 
407

408

409

410

\section{REFERENCES}

Abbaszadegan, M., Hasan, M.N., Gerba, C.P., Roessler, P.F., Wilson, B.R., Kuennen, R., Van Dellen, E., 1997. The disinfection efficacy of a point-of-use water treatment system against bacterial, viral and protozoan waterborne pathogens. Water Res. 31, 574-582.

Adams, M.H., 1959. Bacteriophages, 1st ed. Interscience Publishers, New York, NY.

Agogué, H., Lamy, D., Neal, P.R., Sogin, M.L., Herndl, G.J., 2011. Water mass-specificity of bacterial communities in the North Atlantic revealed by massively parallel sequencing. Mol. Ecol. 20, 258-74. doi:10.1111/j.1365-294X.2010.04932.x

Bertke, E.E., 2007. Composite Analysis for Escherichia coli at Coastal Beaches. J. Great Lakes Res. 33, 335-341. doi:10.3394/0380-1330(2007)33[335:CAFECA]2.0.CO;2

Boehm, A.B., 2007. Enterococci Concentrations in diverse coastal environments exhibit extreme variability. Environ. Sci. Technol. 41, 8227-8232.

Byappanahalli, M.N., Fowler, M., Shively, D., Whitman, R.L., 2003. Ubiquity and Persistence of Escherichia coli in a Midwestern Coastal Stream. Appl. Environ. Microbiol. 69, 4549-4555. doi:10.1128/AEM.69.8.4549

Food and Drug Administration, 2015. Food Safety Modernization Act (FSMA).

Gerba, C.P., Choi, C.Y., 2006. Role of Irrigation Water in Crop Contamination by Viruses. Viruses in Foods 257-264. doi:10.1007/0-387-29251-9_11

Haack, S.K., Fogarty, L.R., West, T.G., Alm, E.W., McGuire, J.T., Long, D.T., Hyndman, D.W., Forney, L.J., 2004. Spatial and temporal changes in microbial community structure associated with recharge-influenced chemical gradients in a contaminated aquifer. Environ. Microbiol. 6, 438-48. doi:10.1111/j.1462-2920.2003.00563.x

Holvoet, K., Sampers, I., Seynnaeve, M., Uyttendaele, M., 2014. Relationships among hygiene indicators and enteric pathogens in irrigation water, soil and lettuce and the impact of climatic conditions on contamination in the lettuce primary production. Int. J. Food Microbiol. 171, 21-31. doi:10.1016/J.IJFOODMICRO.2013.11.009 
ljabadeniyi, O.A., Debusho, L.K., Vanderlinde, M., Buys, E.M., 2011. Irrigation water as a potential preharvest source of bacterial contamination of vegetables. J. Food Saf. 31, 452461. doi:10.1111/j.1745-4565.2011.00321.x

Jones, R.I., Fulcher, A.S., Jayakody, J.K.U., Laybourn-Parry, J., Shine, A.J., Walton, M.C., Young, J.M., 1995. The horizontal distribution of plankton in a deep, oligotrophic lake-Loch Ness, Scotland. Freshw. Biol. 33, 161-170. doi:10.1111/j.1365-2427.1995.tb01157.x

Juahir, H., Zain, S.M., Yusoff, M.K., Hanidza, T.I.T., Armi, A.S.M., Toriman, M.E., Mokhtar, M., 2011. Spatial water quality assessment of Langat River Basin (Malaysia) using environmetric techniques. Environ. Monit. Assess. 173, 625-41. doi:10.1007/s10661-010$1411-x$

Karl, D.M., 1978. Distribution, abundance, and metabolic states of microorganisms in the water column and sediments of the Black Sea. Limnol. Oceanogr. 23, 936-949. doi:10.4319/lo.1978.23.5.0936

Kayed, D., 2017. Microbial Quality of Irrigation Water used in the Production of Fresh Produce in Arizona. University of Arizona.

Kinzelman, J.L., Dufour, A.P., Wymer, L.J., Rees, G., Pond, K., Bagley, R.C., 2006. Comparison of Multiple Point and Composite Sampling for Monitoring Bathing Water Quality. Lake Reserv. Manag. 22, 95-102. doi:10.1080/07438140609353887

Krempin, D.W., Sullivan, C.W., 1981. The seasonal abundance, vertical distribution, and relative microbial biomass of chroococcoid cyanobacteria at a station in southern California coastal waters. Can. J. Microbiol. 12, 1341-1344.

Llirós, M., Gich, F., Plasencia, A., Auguet, J.-C., Darchambeau, F., Casamayor, E.O., Descy, J.P., Borrego, C., 2010. Vertical distribution of ammonia-oxidizing crenarchaeota and methanogens in the epipelagic waters of Lake Kivu (Rwanda-Democratic Republic of the Congo). Appl. Environ. Microbiol. 76, 6853-63. doi:10.1128/AEM.02864-09

Lubo Liu, †, Mantha S. Phanikumar, *, †, Stephanie L. Molloy, ‡, Richard L. Whitman, §, Dawn 
A. Shively, §, Meredith B. Nevers, §, David J. Schwab, II and, Roseł, J.B., 2006. Modeling the Transport and Inactivation of E. coli and Enterococci in the Near-Shore Region of Lake Michigan. doi:10.1021/ES060438K

McDaniel, R.L., Soupir, M.L., Tuttle, R.B., Cervantes, A.E., 2013. Release, Dispersion, and Resuspension of Escherichia coli From Direct Fecal Deposits Under Controlled Flows ${ }^{1}$. JAWRA J. Am. Water Resour. Assoc. 49, 319-327. doi:10.1111/jawr.12022

Mclellan, S.L., Daniels, A.D., Alissa, K., Salmore, A.K., 2001. Clonal Populations of Thermotolerant Enterobacteriaceae in Recreational Water and Their Potential Interference with Fecal Escherichia coli Counts Clonal Populations of Thermotolerant Enterobacteriaceae in Recreational Water and Their Potential Interferenc. doi:10.1128/AEM.67.10.4934

Nationa Renewalble Energy Laboratory, 2009. Concentrating Solar Resource: Direct Normal [WWW Document]. Conc. Sol. Power Radiat. (10 km)—Static Maps.

Pandey, P., Soupir, M., 2014. Assessing linkages between E. coli levels in streambed sediment and overlying water in an agricultural watershed in lowa during the first heavy rain event of the. Trans. ASABE.

Pandey, P.K., Soupir, M.L., Ikenberry, C.D., Rehmann, C.R., 2016. Predicting Streambed Sediment and Water Column Escherichia coli Levels at Watershed Scale. JAWRA J. Am. Water Resour. Assoc. 52, 184-197. doi:10.1111/1752-1688.12373

Rehmann, C.R., Soupir, M.L., 2009. Importance of interactions between the water column and the sediment for microbial concentrations in streams. Water Res. 43, 4579-4589. doi:10.1016/j.watres.2009.06.049

Reicherts, J.D., Emerson, C.W., 2010. Monitoring bathing beach water quality using composite sampling. Environ. Monit. Assess. 168, 33-43. doi:10.1007/s10661-009-1089-0

Reynolds, K.A., Beamer, P.I., Plotkin, K.R., Sifuentes, L.Y., Koenig, D.W., Gerba, C.P., 2015. The Healthy Workplace Project: Reduced Viral Exposure in an Office Setting. Arch. 
471 Sinclair, R.G., Romero-Gomez, P., Choi, C.Y., Gerba, C.P., 2009. Assessment of MS-2 phage

USDA Economic Research Service [WWW Document], 2017. URL https://www.ers.usda.gov/topics/farm-practices-management/irrigation-wateruse/background.aspx (accessed 11.21.17).

Valdez, M.K., Sexton, J.D., Lutz, E. a., Reynolds, K.A., 2015. Spread of infectious microbes during emergency medical response. Am. J. Infect. Control 43, 606-611. doi:10.1016/j.ajic.2015.02.025

Verhougstraete, M.P., Rose, J.B., 2014. Microbial investigations of water, sediment, and algal mats in the mixed use watershed of Saginaw Bay, Michigan. J. Great Lakes Res. 40, 7582. doi:10.1016/j.jglr.2013.11.004

Whitman, R.L., Byers, S.E., Shively, D.A., Ferguson, D.M., Byappanahalli, M., 2005. Occurrence and growth characteristics of Escherichia coli and enterococci within the accumulated fluid of the northern pitcher plant ( Sarracenia purpurea L.). Can. J. Microbiol. 51, 1027-1037. doi:10.1139/w05-091 
Whitman, R.L., Nevers, M.B., 2004. Escherichia coli Sampling Reliability at a Frequently Closed Chicago Beach: Monitoring and Management Implications. Environ. Sci. Technol. 38, 4241-4246. doi:10.1021/ES034978I

Whitman, R.L., Nevers, M.B., Byappanahalli, M.N., 2006. Examination of the watershed-wide distribution of Escherichia coli along Southern Lake Michigan: an integrated approach. Appl. Environ. Microbiol. 72, 7301-10. doi:10.1128/AEM.00454-06

Whitman, R.L., Nevers, M.B., Korinek, G.C., Byappanahalli, M.N., 2004. Solar and temporal effects on Escherichia coli concentration at a Lake Michigan swimming beach. Appl. Environ. Microbiol. 70, 4276-85. doi:10.1128/AEM.70.7.4276-4285.2004

Winfield, M.D., Groisman, E.A., 2003. Role of Nonhost Environments in the Lifestyles of Salmonella and Escherichia coli. Appl. Environ. Microbiol. 69, 3687-3694. doi:10.1128/AEM.69.7.3687

Won, G., Kline, T.R., LeJeune, J.T., 2013. Spatial-temporal variations of microbial water quality in surface reservoirs and canals used for irrigation. Agric. Water Manag. 116, 73-78. doi:10.1016/j.agwat.2012.10.007 
Table 1. Geometric mean \pm the standard deviation of water quality measurements by region.

\begin{tabular}{|c|c|c|c|c|c|c|c|c|c|c|}
\hline Region & $\mathbf{n}$ & $\begin{array}{c}\text { E. coli } \\
\text { (MPN/ } \\
100 \mathrm{ml})\end{array}$ & $\begin{array}{c}\text { Coliforms } \\
\text { (MPN/ } \\
100 \mathrm{ml})\end{array}$ & $\mathrm{pH}$ & $\begin{array}{l}\text { Conduct. } \\
\text { ( } \mu \text { S/cm) }\end{array}$ & $\begin{array}{c}\text { Turbidity } \\
\text { (NTU) }\end{array}$ & $\begin{array}{c}\text { TDS } \\
\text { (mg/L) }\end{array}$ & $\begin{array}{c}\text { Air Temp. } \\
\left({ }^{\circ} \mathrm{C}\right)\end{array}$ & $\begin{array}{c}\text { Water } \\
\text { Temp. }\left({ }^{\circ} \mathrm{C}\right)\end{array}$ & $\begin{array}{c}\text { Relative } \\
\text { Humidity (\%) }\end{array}$ \\
\hline A & 752 & $11.2 \pm 133$ & $826 \pm 956$ & $8.47 \pm 0.42$ & $1420 \pm 403$ & $4.62 \pm 31.6$ & $846 \pm 48.4$ & $27.3 \pm 10.2$ & $20.9 \pm 6.51$ & $18.2 \pm 20.7$ \\
\hline B & 286 & $33.9 \pm 98.7$ & $714 \pm 667$ & $8.63 \pm 0.24$ & $1230 \pm 161$ & $4.32 \pm 31.9$ & $869 \pm 115$ & $22.2 \pm 4.58$ & $22.1 \pm 3.31$ & $24.6 \pm 25.6$ \\
\hline C & 290 & $9.45 \pm 190$ & $1000 \pm 786$ & $8.67 \pm 0.14$ & $1190 \pm 15.7$ & $2.72 \pm 13.2$ & $845 \pm 11.2$ & $23.3 \pm 5.13$ & $16.9 \pm 1.71$ & $29.8 \pm 19.1$ \\
\hline Total & 1328 & $15.6 \pm 143$ & $836 \pm 872$ & $8.54 \pm 0.35$ & $1330 \pm 340$ & $4.07 \pm 28.7$ & $851 \pm 69.2$ & $25.3 \pm 8.81$ & $20.3 \pm 5.56$ & $22.1 \pm 21.8$ \\
\hline
\end{tabular}


514 Table 2. Geometric mean \pm the standard deviation for E. coli and total coliforms by sampling 515 time.

\begin{tabular}{lccc}
\hline Time of day & $\boldsymbol{n}$ & $\begin{array}{c}\text { E. coli } \\
(\text { MPN/100 } \mathrm{ml})\end{array}$ & $\begin{array}{c}\text { Total Coliforms } \\
\text { (MPN/100 ml) }\end{array}$ \\
\hline Before 09:00 & 185 & $28.0 \pm 217$ & $935 \pm 906$ \\
09:00-12:00 & 222 & $22.4 \pm 98.2$ & $826 \pm 894$ \\
12:00-13:00 & 173 & $18.0 \pm 115$ & $908 \pm 935$ \\
After 13:00 & 222 & $13.6 \pm 119$ & $670 \pm 929$ \\
\hline
\end{tabular}

516

517

518

519

520

521

522

523

524 
525 Table 3. Geometric mean \pm the standard deviation for $E$. coli by sample depth and cross-section 526 location.

\begin{tabular}{cccc}
\hline Depth $(\mathbf{m})$ & $\begin{array}{c}\text { Cross-section } \\
\text { Position }\end{array}$ & $\boldsymbol{n}$ & $\begin{array}{c}\text { E. coli } \\
\text { (MPN/100 ml) }\end{array}$ \\
\hline 0 & Bank + Center & 100 & $8.32 \pm 172$ \\
0 & Bank & 49 & $7.81 \pm 204$ \\
0 & Center & 51 & $8.85 \pm 135$ \\
0.61 & Bank + Center & 100 & $8.90 \pm 184$ \\
0.61 & Bank & 50 & $8.70 \pm 168$ \\
0.61 & Center & 50 & $9.11 \pm 201$ \\
1.22 & Bank + Center & 100 & $7.97 \pm 199$ \\
1.22 & Bank & 49 & $8.49 \pm 120$ \\
1.22 & Center & 51 & $7.50 \pm 254$ \\
$0-1.22$ & Bank + Center & 300 & $8.39 \pm 185$ \\
$0-1.22$ & Bank & 148 & $8.33 \pm 166$ \\
$0-1.22$ & Center & 152 & $8.45 \pm 201$ \\
\hline
\end{tabular}

531

532 
537 Table 4. Geometric mean (GM) \pm the standard deviation (SD) for bacteria by distance 538 downstream from canal seeding point.

\begin{tabular}{ccccc}
\hline $\begin{array}{c}\text { Downstream } \\
\text { Distance }(\mathrm{m})\end{array}$ & E. coli (MPN/100 ml) & \multicolumn{2}{c}{$\begin{array}{c}\text { Total coliforms } \\
\text { (MPN/100 ml) }\end{array}$} \\
\cline { 2 - 5 } & $\boldsymbol{n}$ & $(\mathrm{GM} \pm \mathrm{SD})$ & $\boldsymbol{n}$ & $(\mathrm{GM} \pm \mathrm{SD})$ \\
\hline 322 & 15 & $10.5 \pm 19.5$ & 15 & $1,810 \pm 687$ \\
644 & 15 & $7.21 \pm 19.7$ & 15 & $2,030 \pm 583$ \\
966 & 15 & $10.5 \pm 32.3$ & 15 & $1,810 \pm 687$ \\
1288 & 15 & $8.03 \pm 18.1$ & 15 & $2,020 \pm 620$ \\
1609 & 15 & $5.29 \pm 16.5$ & 15 & $1,980 \pm 631$ \\
1931 & 15 & $6.69 \pm 12.7$ & 15 & $2,010 \pm 579$ \\
2253 & 15 & $6.52 \pm 12.9$ & 15 & $1,710 \pm 756$ \\
\hline Total & 120 & & 120 & \\
\hline
\end{tabular}

539 
540 Table 5. Concentrations and geometric mean (GM) \pm the standard deviation (SD) of MS2

541 coliphage by distance downstream from canal seeding point.

\begin{tabular}{|c|c|c|c|c|}
\hline \multirow{2}{*}{$\begin{array}{l}\text { Downstream } \\
\text { Distance }(\mathrm{m})\end{array}$} & \multicolumn{4}{|c|}{ MS2 Coliphage (PFU/100 ml) } \\
\hline & Canal 1 & Canal 2 & Canal 3 & $(G M \pm S D) 544$ \\
\hline 0 & 14,500 & 182,000 & Not Tested & $51,318 \pm 118,462$ \\
\hline 81 & 4,850 & 40,000 & Not Tested & $13,928 \pm 24,855$ \\
\hline 161 & 3,650 & 1,440 & Not Tested & $2,293 \pm 1,563$ \\
\hline 241 & 2,710 & 6,550 & Not Tested & $4,213 \pm 2,715$ \\
\hline 322 & 2,650 & 4,350 & 4,450 & $3,716 \pm 1,012$ \\
\hline 644 & 980 & 2,080 & 790 & $1,172 \pm 696$ \\
\hline 966 & 295 & 1,310 & 301 & $488 \pm 581$ \\
\hline 1288 & 157 & 1,440 & 129 & $308 \pm 749$ \\
\hline 1609 & 71.0 & 325 & 27.0 & $85.0 \pm 161$ \\
\hline 1931 & 28.2 & 166 & 7.00 & $32.0 \pm 86$ \\
\hline 2253 & 215 & 92.0 & $<0.10$ & $9.95 \pm 108$ \\
\hline
\end{tabular}




\section{5}

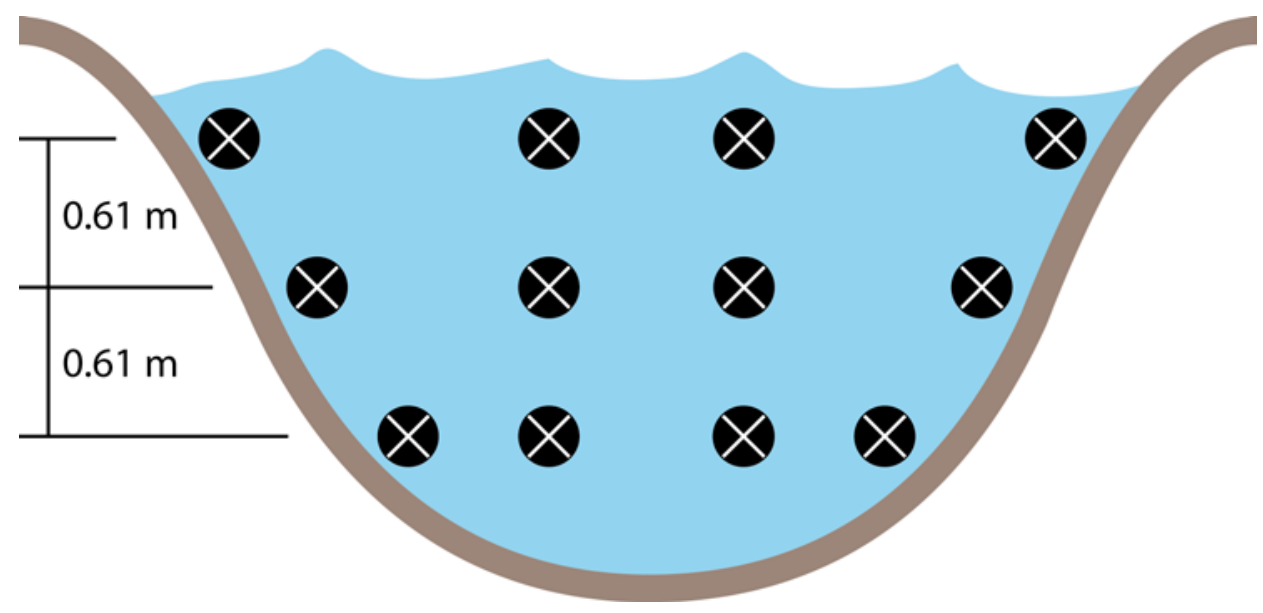

546 Figure 1. Sampling schematic for defining the appropriate canal transect sample collection 547 point.

548

549 

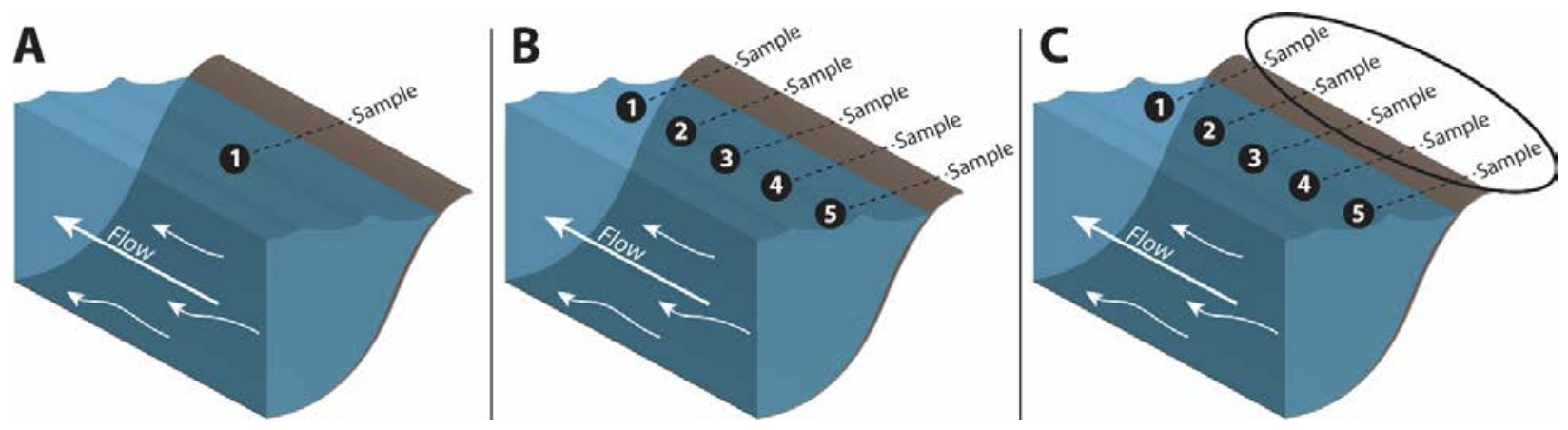

551 Figure 2. Schematic for addressing the most appropriate sampling approach using A) single

552 sample; B) multiple samples, assayed individually then geometric mean calculated; and C)

553 multiple samples, composited into a single sample and then assayed.

554

555 


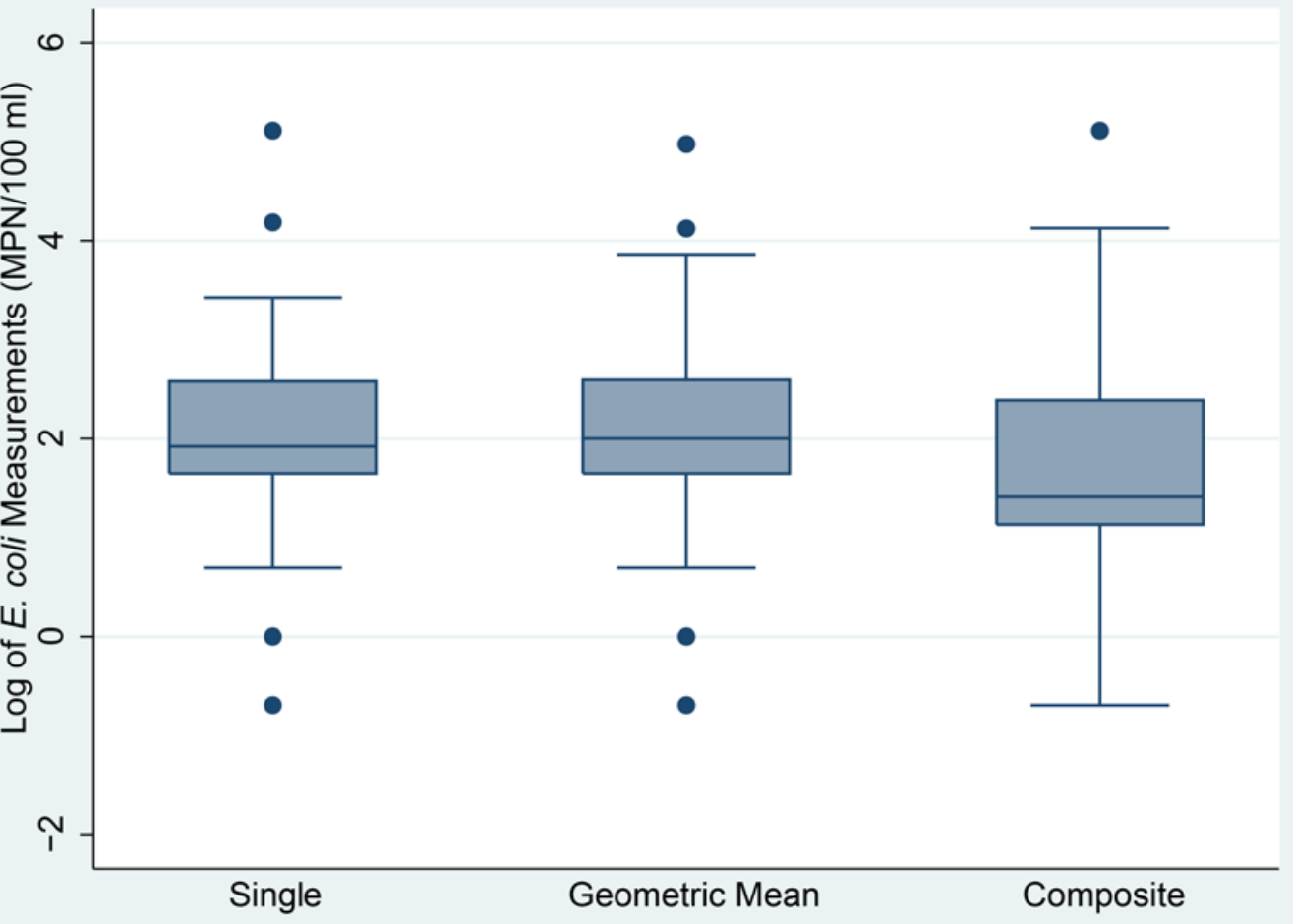

556

557 Figure 3. E. coli measurements from 1) single sample, 2) geometric mean of five samples, and

558 3) a composite of five samples. The box represents the 25th and 75th percentiles, the horizontal

559 line within the box represents the median concentration, the vertical lines extending from each

560 box represent the range of E. coli concentrations (excluding outliers), and the dots represent

561 outliers.

562

563 